\title{
A DINÂMICA DA CONSTRUÇÃO DE SENTIDOS NO INTERIOR DOS INTERTÍCIOS DAS FORMAÇÕES DISCURSIVAS, DOS ACONTECIMENTOS E DAS ASSEMBLAGENS
}

\author{
Adilson Crepalde ${ }^{1}$ \\ Carlos Fabrício de Souza Ribeiro de Castro ${ }^{2}$
}

\begin{abstract}
RESUMO: Este trabalho consiste no estudo de um de cartaz encontrado em praça pública depois de uma manifestação em defesa da liberdade sexual e de gênero. Objetiva-se discutir o processo de construção de sentido, refletindo-se sobre o enunciado do cartaz que manifestava apoio à luta, e o fazia em nome do amor cristão. Para atingir o objetivo proposto, o enunciado é estudado do ponto de vista do chamado pensamento rebelde, com destaque para às reflexões de Michel Foucault. $\mathrm{O}$ estudo mostra como um simples e aparentemente inocente cartaz recobre toda a complexidade do processo de construção de sentido, o que deve interessar não somente ao analista do discurso, ao filósofo e ao semanticista, mas também a todos que entendem que compreender os processos de construção de sentido ajuda nas interações sociais, sobretudo aquelas que se passam dentro do espaço escolar.
\end{abstract}

PALAVRAS-CHAVE: Sentido. Construção. Forças. Dinâmica. Devir.

\begin{abstract}
This article consists of a study of a placard left on the ground of a public square after a rally in defense of sexual and gender freedom. We aims at discussing the meaning construction process, by thinking on the placard wording that manifested support to the fight for sexual and gender freedom, and it did that in the name of Christian love. To achieve our goal, the wording is studied from the so called rebel thought point of view, with emphasis on the Michel Foucault's thoughts. The study shows that a simple and an apparently innocent placard encompass a complex and dynamic process of meaning construction, what may be of interest not only to discourse analysts, to philosophers and semanticists but also to all those who feel that studies of the meaning construction process can contribute to the social interaction, including those that take place in school spaces.
\end{abstract}

KEYWORDS: Meaning. Construction. Forses. Dynamics. Becoming.

\section{Considerações preliminares}

Este trabalho consiste na análise de um cartaz encontrado em praça pública por ocasião de um evento realizado em defesa da diversidade sexual e de gênero (DSG) por militantes e simpatizantes. O cartaz nos chamou a atenção, em relação aos outros, pela maneira como havia sido escrito e pela mensagem religiosa que veiculava, aparentemente

\footnotetext{
${ }^{1}$ Universidade Estadual de Mato Grosso do Sul. Docente do Curso de Letras Hab. Português-Inglês, UEMS, Dourados/MS, Brasil. E-mail: crepalde@uems.br

${ }^{2}$ Universidade Estadual de Mato Grosso do Sul. Discente do Curso de Letras Hab. Português-Espanhol, UEMS, Dourados/MS, Brasil. E-mail : carlinhosla@ hotmail.com
} 
fora do contexto, pois defendia a diversidade sexual e de gênero por meio de um discurso com características religiosas. Essa aparente contradição nos pareceu uma oportunidade de refletir sobre os processos de construção de sentido, pois aquele enunciado se apresentava como um elemento novo, uma alternativa nas discussões sobre DSG e das causas LGBTQI+ que, neste momento histórico, têm sido marcadas por disputas discursivas dicotômicas e radicais. O evento traduzia essa dicotomia, pois os discursos exaltavam diversas causas do LGBTQI+ e se construíam em oposição a um discurso, que segundo os enunciadores, era reacionário e calcado em passagens da Bíblia. Escolhemos o referido cartaz por se apresentar como algo intersticial, o que nos levou a perguntar o que o estudo desse cartaz poderia dizer sobre a dinâmica dos processos de construção de sentido.

Muitos estudos têm sido realizados com base nas reflexões de pensadores, como Saussure, Pierce, Wittgenstein, Greimas e tantos outros que têm subsidiado e desencadeado inúmeros trabalhos importantes sobre o processo de construção de sentido. Trata-se de um assunto complexo que tem sido abordado do ponto de vista socio-histórico, cognitivo, ideológico, psicológico, estruturalista, etc. Um assunto inesgotável que interessa a todos aqueles que se esforçam para compreender como se dá o funcionamento da linguagem, os processos interativos por meio da linguagem e como os sentidos são elaborados nessas interações.

Neste trabalho, optamos por fazer nossa análise apoiados no pensamento dito rebelde de Deleuze (1996, 2003, 2019, Abecedário de Gilles Deleuze); Derrida (1997, 2002); com destaque para as discussões de Foucault (1971, 1985, 1999, 2000, 2008). Além dos referidos autores, recorremos a reflexões teóricas de outros pensadores, principalmente de Bakhtin, pois entendemos que esse autor, embora tenha construído sua teoria com base em premissas diferentes de Deleuze, Derrida e Foucault, oferece conceitos para se compreender a dinâmica do processo de construção de sentido que acreditamos serem pertinentes para o estudo em tela.

As reflexões proporcionadas por este trabalho são esforços em problematizar os processos de construção de sentido, na medida em que levam a perguntar sobre os jogos de poder, sobre as dispersões, as rupturas, os interstícios, as ausências, as brechas, as linhas de fuga, as contradições, as vozes, etc., que os permeiam. .

Assim, procuramos refletir sobre as ações que acontecem no interior das formas de dizer, isto é, uma forma de discurso ou formação discursiva - entendida neste trabalho como um meio que percorre todos os espaços e tempos -. Nesses espaços, os sentidos só se 
concretizam discursivamente, por meios de maneiras de arranjar os elementos significativos (estratégias) e por meio de práticas sociais (Orlandi, 2011).

Essa concretização permite observar a manipulação dos elementos simbólicos no processo desencadeado pela necessidade humana de produzir sentidos. Desse modo, esses conjuntos relacionais são caracterizados por regras de organização como nos remete o conceito de "Formação Discursiva" em Foucault (2008). Esse recorte teórico nos pareceu apropriado, pois visávamos discutir não apenas a ideologia, o significado, a história por trás do enunciado, mas quais forças que movem o discurso e o dizer, forças essas que fazem emergir o sentido dentro das relações que o condicionava. No entanto, nos pareceu importante levar em consideração também como os agentes se movem, como se afetam, como buscam territórios para por em jogo suas potencias que investem no processo Neil (2017). Buscamos entender o cartaz como resultado de ato criativo e responsivo, um ato dialógico carregado de vozes, mas que busca manter uma individualidade, um ponto de convergência. Entendemos o cartaz como um ato irrepetível que mostra os desejos e emoções de agentes atravessados pelo mundo. Nesse sentido, não é contraditório colocar Bakhtin, Deleuze e Foucault na mesma análise, pois, embora, para Bakthin, o sentido emirja de um sujeito histórico concreto no interior dos modos de produção, pelo qual os valores são acionados no processo de constução de sentido, esses autores colocam o sentido em uma construção coletiva como em um grande diálogo, e essa construção está sempre situada, seja em uma formação discursiva, seja em uma assemblage, seja em um acontecimento.

Os sujeitos se constituem em relação com o outro e se fazem outros dentro desses enquadramentos e seguem normas para participar do processo aberto no diálogo. Deleuze, Foucault e Bakhtin retiram o sentido das mãos do sujeito iluminista, consciente e todo poderoso. Para Foucault, os participantes da construção do sentido são vértices de poder, para Bakhtin são atravessados por vozes e para Deleuze por afetos, por volições, mas são determinados por forças imanentes, por possibilidade de ação socio-historicamente desenvolvidas. Dessa maneira optamos por uma teoria que possibilitasse demonstrar a complexidade do processo, apontando para o inconsciente, para as memorias, para as potencias que habitam o ser humano. Nesse processo, devemos destacar diversas forças criativas que culminam na carnavalização, nas linhas de fuga e nas rupturas, na construção de novos objetos. Muito embora essas forças sejam tolhidas pelas ideologias, pelas formações discursivas e pelas forças centrípetas das relações, algo novo acaba sempre acontecendo, e é o que o cartaz revela. Revela um discurso como ação, engendrado por forças que elaboram 
PERcursos Linguísticos • Vitória (ES) •v. 10 •n. 25 • 2020 • ISSN: 2236-2592 • Dossiê:

Discursos de resistência e corpos (re)existentes •

os sentidos e que constituem os sujeitos.

Para buscar compreender o cartaz nessa perspectiva, na primeira parte deste trabalho, apresentamos o contexto em que se encontrava o enunciado em reflexão. Na segunda parte, refletimos sobre quais forças e os elementos de sentido que se constituem no cartaz. $\mathrm{Na}$ terceira parte, fazemos nossas considerações finais, comentando a pertinência do uso dos conhecimentos teóricos, os resultados alcançados e às possibilidades de aprofundamento sobre os processos de construção de sentido.

\section{A praça como texto e contexto}

Os enunciados que ecoavam na praça eram marcados por uma infinidade de linguagens: falas, gestos, danças, roupas e músicas. A praça converteu-se em um suporte de um texto heterogêneo, um espaço de relação de signos em convergência e divergência. Esse texto dinâmico e móvel, ao mesmo tempo que afirmava à DSG e os direitos dos LGBTQI+, se convertia em um espaço de denúncia em relação aos discursos contrários à diversidade e demarcava um posicionamento político no debate.

Inúmeros grupos de LGBTQI+ e simpatizantes da causa compunham o discurso da praça, formando uma totalidade, mas também impondo suas diferenças. Cada grupo tinha seu modo de se expressar por meio de cores, de vestimentas, de danças, de palavras de ordem, etc. Seus enunciados tratavam do mesmo objeto, mas não com o mesmo olhar, assim formavam uma unidade discursiva notadamente marcada pela heterogeneidade, por dispersões, rupturas e disputas de poder internas; todavia, essa totalidade de diferenças impunha uma fronteira, uma diferença em relação a outros discursos (Foucault, 2008).

Não se tratava de uma unidade discursiva organizada linearmente e configurada na alternância entre interlocutores que respeitavam seus turnos de fala, mas sim, de um rizoma, um sistema aberto, como afirmou Deleuze (1996). Um rizoma que havia um núcleo irradiador do qual se expandiam os signos verbais e não verbais para todos os lados, atingindo outros núcleos que recebiam essa irradiação e, ao mesmo tempo, emitiam outras irradiações. Por meio dessas trocas e na sua multiplicidade, formava-se uma rede de relações extremamente complexa e heterogênea, com vozes em conjunção e em disjunção, um aglomerado de assemblagens eram formadas por meio de agenciamentos criativos, que misturavam toda sorte de elementos significativos. Esses enunciados multimodais eram marcados por signos verbais e não verbais multicoloridos que se manifestavam nos corpos, nas vozes e nas roupas 
- escrituras ambulantes que se combinavam e se recombinavam em semelhanças e diferenças.

Havia também momentos em que palavras de ordem pareciam acabar com as diferenças, impelindo todos os sujeitos para um centro, marcando a filiação em torno das premissas básicas do discurso em prol da liberdade e da DSG e da causa dos LGBTQI+. Essas palavras de ordem, ao mesmo tempo em que exaltavam o direito de escolha e a liberdade de orientação em relação às distintas sexualidades, impunham uma fronteira em relação ao discurso contrário à DSG.

Nesses momentos de convergência, essa unidade de vozes da praça demarcava às fronteiras entre o discurso da DSG e do discurso contrário, denominado, pelas palavras de ordem, de reacionário, homofóbico e patriarcal. Os enunciados da praça marcavam um posicionamento radical, desautorizando argumentos do discurso ao qual se opunham, atacando suas premissas de base, inclusive aquelas fundamentadas na moral ancorada na Bíblia.

No meio do mar de signos que tomou a praça e que impunha diferenças internas entre os dois discursos radicalmente opostos, apareceu um enunciado estampado em um cartaz jogado no chão com uma caraterística peculiar. Um conjunto de signos linguísticos encerrando vozes, um enunciado convidando o interlocutor a se dirigir a outro modo de ver as questões relacionadas às sexualidades e aos gêneros. Um enunciado que seduzia os olhares dos interlocutores para uma tese contra homofobia, porém elaborada por pessoas que se afirmam cristãs. O cartaz chamava a atenção pela articulação da linguagem, pela argumentação e pela ousadia de buscar um espaço, uma possibilidade de vir a ser dos sentidos dentro daquele contexto.

\section{A maquinaria da inocência}

Figura 1 - Cartaz

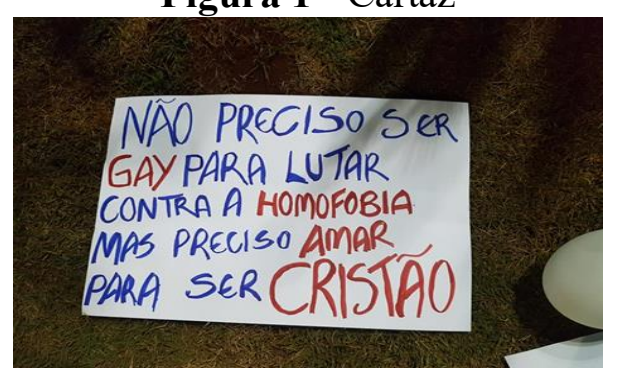

Fonte: Foto de Carlos Fabrício de Souza Ribeiro de Castro na parada da diversidade em Dourados/MS 
Ao se olhar para o cartaz, depreende-se rapidamente que se trata de uma voz contra a homofobia e em favor das causas LGBTQI+. Podia-se dizer que se trata de mais uma manifestação de simpatizantes da causa e ponto. No entanto, uma leitura mais demorada e que leve em consideração a forma como o cartaz foi escrito, a maneira como o conteúdo foi organizado e as condições de produção desse enunciado pode nos levar a importantes reflexões. Pode ajudar a compreender as diversas estratégias para gerar efeitos de sentido e as condições e possibilidades de emergência de um objeto vir a ser ou se tornar dentro de uma formação discursiva.

\begin{abstract}
No caso em que se puder descrever, entre um (sic) certo número de enunciados, semelhante sistema de dispersão, e no caso em que entre os objetos, os tipos de enunciação, os conceitos, as escolhas temáticas, se puder definir uma regularidade (uma ordem, correlações, posições e funcionamentos, transformações), diremos, por convenção, que se trata de uma formação discursiva (FOUCAULT, 2008, p. 47).
\end{abstract}

Dessa maneira, começamos pela organização dos signos na confecção do enunciado que busca estabelecer uma verdade, e que é feito de uma determinada maneira. Nesse sentido não se toma o enunciado da praça como um mero enunciado do dia a dia, mas uma maneira de falar.

\footnotetext{
Não se trata, todavia, de qualquer ato discursivo: enunciados do cotidiano, por exemplo, mas de "atos discursivos sérios", isto é, enunciados que manifestam uma incessante "vontade de verdade". Esses enunciados sérios então se relacionam com enunciados do mesmo ou de outros tipos e são condicionados por um conjunto de regularidades internas, constituindo um sistema relativamente autônomo, denominado de formação discursiva (BARONAS, 2011, p. 385 ).
}

O enunciado é iniciado por um advérbio de negação, o que já causa um efeito de sentido e mostra um estilo de argumentação. O advérbio "não" no início de enunciados é uma característica de enunciados injuntivos, religiosos e panfletários tanto escritos como orais, um recurso que marca enfaticamente o posicionamento radical do sujeito discursivo conferindo-lhe uma identidade inequívoca e impondo uma fronteira rígida entre o sujeito e aquilo que se nega. Desse modo, ao abandonarmos a rigidez dos gêneros discursivos e centrarmos mais no agenciamento do processo de construção de sentido, percebemos que a força do advérbio "não" é relativizada e utilizada com perspicácia, pela capacidade criativa de relacionar signos e montar, dentro de uma determinada situação, uma unidade significativa. 
${ }^{3}$ Uma "assembalege" não é apenas uma mistura heterogênea de elementos; essa definição é demasiadamente simplicista. A definição da expressão francesa "agencement" não se refere simplesmente a uma composição heterogênea, mas implica a um processo construtivo que dá forma a um tipo de arranjo específico (NAIL, 2017, p. 24, tradução nossa).

Dessa maneira, pode-se tomar o enunciado como uma unidade que fala muito mais do que aquilo que aparentemente enuncia, pois carrega outros dizeres e aponta sempre para o outro, tratando de construir um objeto novo, algo criativo e elaborado dentro de uma determinada situação. Os sentidos se revelam e são fortes pelo caráter coercitivo do signo, como afirmou Foucault (2000).

Ao aprofundarmos um pouco mais a leitura, podemos ver que a frase: "não preciso ser gay para lutar contra a homofobia", diz muito mais do que uma opinião de simpatizantes e mobiliza outras atitudes que não somente destes e para além deles por revelar um chamamento muito maior, sobretudo quando lemos a frase ligada pela conjunção "mas" à sentença seguinte: "mas preciso amar para ser cristão". O "mas" aqui cria um efeito de sentido estabelecendo não uma relação de contrastividade, mas de condição. Não preciso ser gay, mas necessariamente preciso amar para ser cristão. Indiretamente, o enunciado mostra o lugar de quem fala, anuncia uma maneira de dizer, traz marcas ideológicas e socio-históricas profundas e admite sutilmente e diminui a tensão entre as categorias "gay" e "cristão". Quebra-se a rigidez das fronteiras entre duas categorias consideradas opostamente dicotômicas no âmbito do discurso religioso mais ortodoxo e abre uma possibilidade de conciliação entre duas formações discursivas contrárias.

A condição de estar dos sujeitos encontra-se entre os contrários e anuncia a possibilidade de um interstício, de um espaço de construção de sentido que sugere a negação de uma das características do discurso religioso ortodoxo que é o princípio da não contradição. Isto é, não se pode ser duas coisas diferentes a um só tempo.

Nessa linha de raciocínio, o enunciado parece querer desconstruir a premissa bíblica de que o homem foi feito por Deus para cumprir a função de homem e se relacionar sexualmente unicamente com mulheres, premissa da qual derivam todos os juízos que envolvem questões sobre sexualidade no contexto do discurso religioso ortodoxo. Um discurso que desbiologiza o sexo e os corpos, como traz Foucault (1985). O enunciado parece

\footnotetext{
${ }^{3}$ Do Original: An assemblage is not just a mixture of heterogeneous elements; this definition is far too simplistic. The definition of the French word agencement does not simply entail heterogeneous composition, but entails a constructive process that lays out a specific kind of arrangement.
} 
PERcursos Linguísticos • Vitória (ES) •v. 10 •n. 25 • 2020 • ISSN: 2236-2592 • Dossiê:

Discursos de resistência e corpos (re)existentes •

querer contestar o que Derrida (2006, 1997), chama de pensamento logocêntrico, e se apresenta como uma tentativa de desconstrução.

A "racionalidade" - mas talvez fosse preciso abandonar esta palavra, pela razão que no final desta frase - que comanda a escritura assim ampliada e radicalizada, não é mais nascida de um logos e inaugura a destruição, não a demolição mas a desedimentação, a desconstrução de todas as significações que brotam da significação de $\log$ os (DERRIDA, 2006, p.13).

É possível dizer que é algo criativamente engendrado para a situação, consiste em uma proposta de desconstrução, elaborado com características de um tipo de discurso, mas que surge ao mesmo tempo como uma ruptura a essa maneira de dizer anterior, trazendo novos contornos e relações ao discurso ortodoxo. No entanto, um olhar mais cuidadoso vai fazendo surgir contradições. Por exemplo, o verbo "precisar" é usado duas vezes; na primeira, forma uma locução com o verbo "ser", e, na segunda, com o verbo “amar". Neste caso remete a uma condição necessária para ser cristão, ou seja, não se pode ser cristão e não amar. Uma leitura que se detenha somente nos elementos significativos pode constatar que o verbo "amar" remete ao amor incondicional de Cristo. No entanto, se buscarmos entender a escritura, o verbo “amar" aparece como uma categoria intersticial complexa e contraditória, um espaço no qual cabem os diferentes, ou seja, gays e cristãos. $\mathrm{O}$ enunciado cria mais um grande efeito de sentido, destacando o amar como uma categoria pacificadora, incontroversa, uma tentativa de apagamento das contradições e violências que encerram o fato de ser gay, cristão e amar (Derrida, 2006).

Sagazmente este cartaz interpela a um só tempo, nas entrelinhas do enunciado, tanto os cristãos como os defensores da causa LGBTQI+. Dessa maneira, se apresenta como uma terceira via no processo de construção do sentido, instigando os interlocutores a agirem, a mudarem suas posições, insinuando de maneira sutil que ambos devem amenizar suas posições de radicalidade e convergirem para o espaço do amor cristão.

O verbo "amar" funciona como um operador lógico que impõe uma categorização rígida, por meio da categoria "amar incondicionalmente". Nesse sentido, a argumentação organizada no cartaz toma forma de raciocínio silogístico, ou seja, há uma premissa maior, uma premissa menor e a conclusão Aristóteles (1979). Nesse formato lógico, todo cristão necessariamente deve amar incondicionalmente. Se você não ama incondicionalmente, logo você não é cristão. Esse tipo de raciocínio impõe o princípio do terceiro excluído, ou seja, 
não há possibilidade de outro resultado nesse cálculo lógico dedutivo. Assim, o enunciado que parecia ser uma ruptura com o logocentrismo, assume esse formato de construir sentido.

A categoria "cristão" aparece grafada em letra maiúscula e em vermelho. O uso dessa cor remete a um significado convencional na cultura brasileira que tem sido usada nos mais variados tipos de enunciados como recurso icônico para chamar a atenção, para dar mais destaque e simbolizar fortes emoções e sentimentos.

Os critérios para distinguir um fenômeno visual estão imbricados com o uso da nossa linguagem, do que entendemos pela palavra vermelho, de como podemos distinguir um amarelo-alaranjado de um laranja-avermelhado, enfim, como o fenômeno cromático pressupõe uma gramática das cores (GIANNOTTI, 2010, p. 98).

Todavia, além do significado convencionalizado pela cultura, o vermelho do cartaz estabelece uma relação de diferença com as outras cores, criando espaços que geram mais sentidos, pois é no jogo das diferenças, das presenças e das ausências e nos espaços em branco que surgem outros sentidos, além daquele evocado pela letra, pela cor, pela forma e outros elementos que compõem a representação de algo (DERRIDA, 2006).

E é nesse jogo complexo, realizado por meio de um enunciado arranjado de maneira sutil, que o outro é interpelado; é nesse embate de forças discursivas que o enunciado constrói sentido, fazendo vir a ser o objeto da sexualidade ou sexual, moldado segundo um conjunto de regras (FOUCAULT, 2000).

Ao olhar para o enunciado, deve-se buscar compreender todas as condições de possibilidade de sua existência e não somente seu significado em si (apoio à luta em defesa da DSG). Isto quer dizer que o cartaz é organizado segundo regras de uma formação discursiva, cuja premissa de base parte sempre do um sujeito transcendental, que no caso é o Cristo e seu amor incondicional.

Essa premissa de amor maior que compreende tudo, aceita tudo e promove a paz põem o foco sempre no outro, no bem-estar do outro, um tipo de discurso apelativo que constrói justificativa com base na transcendentalidade do Cristo, colocando em suspensão os processos socio-históricos, as contradições e a complexidade do ser humano.

Esse efeito de sentido está na força da palavra "cristão" que está grafada em vermelho e em caracteres maiores que as outras palavras, o que dá destaque à palavra "cristão" no jogo entre os significantes. Além disso, a cor vermelha é um signo icônico que evoca uma multiplicidade de sensações desencadeadas pela lembrança do próprio sangue do Cristo e está relacionada à paixão, que no caso tem a ver com a paixão do Cristo em relação aos humanos. 


\title{
PERcursos Linguísticos • Vitória (ES) •v. 10 •n. 25 • 2020 • ISSN: 2236-2592 • Dossiê: \\ Discursos de resistência e corpos (re)existentes •
}

\begin{abstract}
As raízes podem formar-se de várias maneiras. Por onomatopeia certamente, que não é expressão espontânea, mas articulação voluntária de um signo semelhante: fazer com a voz o mesmo ruído que faz o objeto que se quer nomear. Por essa utilização de uma semelhança experimentada nas sensações: A impressão da cor vermelha, que é viva, rápida, dura à vista [...] (FOCAULT, 2007, pág. 151).
\end{abstract}

O cartaz impõe uma regra básica: proceder pelo amor como o único caminho que não só leva ao paraíso, mas também soluciona problemas terrenos. Isso tem um efeito de sentido muito forte em uma sociedade religiosa e humanista como a brasileira, pois o poder do sujeito transcendental não é contestado, nem é contestada a força do amor.

O enunciado também põe em cheque as contradições daqueles que se dizem cristãos, mas que, em certos momentos, em vez de seguir o mandamento do Cristo, optam, convenientemente, por seguir orientações do Antigo Testamento para fundamentar suas posições contrárias à diversidade de sexo e de gênero. $\mathrm{O}$ enunciado aponta para essa contradição, pois os mandamentos do Cristo vieram justamente para substituir os Antigos Mandamentos, colocando o Amor maior acima de qualquer outra lei.

O cartaz demonstra as possíveis mudanças no processo de construção do objeto sexualidade que emergem dos jogos de poder. Ao anunciar um cristão capaz de compreender diferentes manifestações sexuais, enuncia um novo objeto, uma mudança na série histórica da construção de um objeto dentro de uma mesma formação discursiva. Um objeto que nasce nas brechas, nos interstícios, nas contradições e no exercício de poder. Um objeto que nasce das contradições no interior da mesma formação discursiva, mas também nos interstícios entre formações discursivas diferentes.

\footnotetext{
Diremos, pois, que uma formação discursiva se define (pelo menos quanto a seus objetos) se se puder estabelecer um conjunto semelhante; se se puder mostrar como qualquer objeto do discurso em questão aí encontra seu lugar e sua lei de aparecimento; se se puder mostrar que ele pode dar origem, simultânea ou sucessivamente, a objetos que se excluem, sem que ele próprio tenha de se modificar (FOUCAULT, 2008. p. 55).
}

O enunciado do cartaz chama a atenção dos cristãos que excluem os defensores da DSG e dos LGBTQI+, ou seja, entra em conflito com aqueles que pertencem à mesma formação discursiva, e o fazem dentro da lógica e do estilo dos enunciados utilizados pelo conjunto dos sujeitos que pertencem a essa formação. Isso mostra que as formações discursivas não são espaços de concordância, mas espaços de rupturas, da incompletude, do 
eterno jogo de poder nos processos de construção de objetos e de verdades como afirmou Foucault (2008).

O cartaz instaura um espaço enunciativo no qual o "eu" desse espaço configura-se em um agente ligado pelas relações de poder a uma ideologia e a um modo de dizer que interpela o "tu" do espaço enunciativo, no qual pode ser entendido tanto como os cristãos que não toleram a liberdade sexual como os que defendem à DSG.

O enunciado do cartaz atinge dois interlocutores diferentes, filiados a duas formações discursivas diferentes. O apelo ao amor também foi o ponto de intersecção utilizado no enunciado do cartaz para iniciar um diálogo com os defensores da diversidade sexual e de gênero. $\mathrm{O}$ amor é um sentimento libertário, por isso cria possibilidades de convivência dos diferentes e contingencia outros tipos de relações entre os seres humanos, para além das convencionais. Nesse sentido, o enunciado sagazmente estabelece uma relação entre o amor de Cristo e o amor libertário, no entanto, afirma que o amor de Cristo deve ser colocado em primeiro plano, pois é somente nesse espaço de fala ou pensamento que há a possibilidade de incluir todos os diferentes, inclusive aqueles que pensam contra a questão da diversidade sexual e de gênero.

A maneira como o cartaz foi escrito estabelece um diálogo e possibilita a participação no evento, funcionando também como um pedido de licença. A participação oportuniza a prática social cristã que é a de frequentar espaços ocupados pelas minorias, pelos perseguidos, pelos incompreendidos. A maneira como o cartaz está escrito chama a atenção para como os sentidos são elaborados nos interstícios, na opacidade e no poder da ambiguidade e da ambivalência da linguagem.

No enunciado, é possível compreender a tentativa de fertilizar o interstício, a brecha, para fazer vir a ser um novo objeto. Nesse caso a sexualidade representa-se no interior da linguagem e encontra-se, como afirma Foucault (2007, p. 93), "no interstício da ideia, nesse tênue espaço onde ela joga consigo mesma, decompondo-se e recompondo-se".

O enunciado provoca efeitos de sentido jogando com o ser e o não ser, apresentandose em favor de uma suposta liberdade, mas que está sujeita ao amor de Cristo. Nesse sentido, o discurso interdita sem aparentemente interditar na linguagem.

O ciclo da interdição: não te aproximes, não toques, não consumas, não tenhas prazer, não fales, não apareças; em última instância não existirás, a não ser na sombra e no segredo. Sobre o sexo, o poder só faria funcionar uma única lei de proibição. Seu objetivo: que o sexo renunciasse a si mesmo. Seu instrumento: a ameaça de um castigo 


\section{PERcursos Linguísticos • Vitória (ES) •v. 10 •n. 25 • 2020 • ISSN: 2236-2592 • Dossiê: \\ Discursos de resistência e corpos (re)existentes •}

que nada mais é do que sua supressão. Renuncia a ti mesmo sob a pena de seres suprimido; não apareças se não quiseres desaparecer. Tua existência só será mantida à custa de tua anulação. O poder oprime o sexo exclusivamente através de uma interdição que joga com a alternativa de duas inexistências (FOUCALUT, 1988, p. 94).

Nesse sentido, o enunciado mostra a construção de objetos nas bordas, nos interstícios de definições rígidas. O sentido nasce das relações de vários feixes de poder, nas ausências, na força criativa do devir. Uma construção plasmada na linguagem, um processo no qual o ser humano age sobre os signos, compartilhando coisas (objetos, imagens, representações e significados) nos jogos de alteridade, no processo dialógico inacabado de construção de sentido que fazem vir a ser outros significados nos mesmos espaços discursivos sobre os mesmos objetos.

O excedente de minha visão, com relação ao outro, instaura uma esfera particular da minha atividade, isto é, um conjunto de atos internos ou externos que só eu posso préformar a respeito desse outro e que o completam justamente onde ele não pode completar-se. Esses atos podem ser infinitamente variados em função da infinita diversidade das situações em que a vida pode colocar-nos, a ambos, num dado momento (BAKHTIN, 1997, p. 44).

Os indivíduos, pelos sentidos, criam suas identidades, sendo possível amalgamar várias identidades no interior da sociedade, isso faz os grupos serem representados e representarem-se nos mesmos espaços e disputá-los, num conflito e numa tensão discursiva, observada, instituída e presente na linguagem dos sujeitos, como observado na materialidade em estudo.

O poder de ser alguém se faz quando se cria identidades condicionadas a um espaço de fala que os sujeitos adotam dentro das relações de poder, agindo sobre o espaço de fala e potencializando-o naquilo que acreditam e aceitam como verdade. Uma verdade sempre parcial que precisa do espaço discursivo para viver sua parcialidade, mas também sua reiteração (FOUCAULT, 1985). Esse saber que emana em torno das identidades que tem a ver com convicção ideológica, com assimilação de valores e formas culturais, com a necessidade de pertencimento e com o desejo insaciável de sentido que torna o processo de construção de sentido mais amplo, abrangente e complexo.

Nessa perspectiva, os locutores, fazendo uso do verbo amar, propõem a liberdade e a prisão, insinuado que os interlocutores podem ser o que quiserem, desde que amem. Destacam a liberdade que o amor possibilita, mas escamoteiam as regras e deveres que esse amor impõe. Assim, constroem uma imagem ambígua como estratégia argumentativa para 
convencer seus interlocutores a aderirem ao seu ponto de vista. Os interlocutores, diante dessa teia argumentativa, são instados a participar em outra modalidade de jogo, regido por outro conjunto de regras. Dessa maneira, em nome da paz, aqueles que escreveram o cartaz fazem a guerra dos sentidos, tentando impor uma maneira de ver o mundo por meio de táticas sutis que visam à derrota final do outro. $\mathrm{O}$ cartaz permite pensar em uma tática de guerra que escolhe o flanco para atuar, para derrotar dois exércitos de sentido a um só tempo.

Essa complexidade só se revela com o trabalho do arqueólogo quando escava signos organizados em papel em branco, espaço que se oferece ao traço, à trama na qual viceja o sentido. Os traços, nesse papel em branco, criam um novo espaço, um mapa que traz indicativos do caminho percorrido, um mapa que se apresenta ingênuo e cristalino na sua proposta de propor a paz. Todavia, o arqueólogo pode mostrar as camadas que recobrem a mensagem, que, ao serem removidas, mostram que a ingenuidade pode ser astúcia e paz pode ser tática de guerra.

A cor vermelha expressa uma pausa, um ponto final, mas também uma sequência não linear de signos formada por uma organização sintagmática que sugere uma leitura vertical, uma categorização e uma possível intersecção entre essas categorias. Existe um suporte gramatical que dá sustentação ao enunciado traçado no fundo branco que permite o jogo com as cores e a construção de sentidos em torno dos eixos identidade, sexualidade e pensamento cristão.

A maneira como o enunciado foi elaborado possibilita pensar como os interlocutores foram aliciados para o ato de interlocução. O cartaz convida para um encontro, para um engajamento para a instalação de um complexo processo dialógico Bakhtin (1997). Nesse processo, o "eu" do discurso se apresenta como um eu investido de uma maneira de falar; no entanto, a radicalidade da voz cristã tenta ser apagada no jogo dialógico.

Apenas um amor desinteressado segundo o princípio eu o amo não porque ele é bom, mas ele é bom porque o eu amo, apenas a atenção amorosa interessada é capaz de desenvolver uma força suficiente poderosa para abranger e reter a multiplicidade do Ser, sem empobrecê-la ou esquematizá-la. Apenas o amor é capaz de ser esteticamente produtivo; apenas em correlação com o amado é possível a multiplicidade plena (BAKHTIN, 1993, p. 81-82).

A voz cristã como a única possibilidade de solução de um impasse joga com os outros do discurso, com os defensores da DSG e com os cristãos intolerantes a um só tempo. Coloca-os de maneira sutil como radicalidades a serem vencidas, e o faz impondo sutilmente 
outra radicalidade. Uma voz que se constrói a partir de outras vozes e estabelece uma identidade, um espaço de pertencimento. A polifonia do cartaz (...) não é mosqueteira-todos por um; também não é platônica - muitos em um. É Dostoiévskiana-muitos em um, pertença pela diferença, unidade pluralizada (SHAFTER, 2011, pg. 3). E o jogo nesse processo não significa somente possibilidades de ações dentro de regras, mas um feixe de possibilidades de maneiras de agir que encerra a ideia de manipular, ter prazer, de zombar, representar teatralmente, etc., elementos evocados por Bakhtin quando trata da carnavalização.

No enunciado em questão, a primeira pessoa circunstancia-se com a segunda, já que a imagem do eu é a partir do outro, seja afirmando a si mesmo ou negando o outro, como diz Bakhtin em "Para uma Filosofia do Ato", essa é a consciência a ser desperta no Ser. A respeito do dialogismo, ele coloca que o locutor se insere e se atravessa no interior desse ir e vir dialógico, um movimento que entrelaça e se choca entre aquilo que é e não é, tentando modular o outro e a si mesmo - esse é o choque do acontecimento que se move na eventicidade no Ser, cobrando dele uma atitude responsiva. $\mathrm{O}$ enunciador, como trata Orlandi (2011), tenta deslocar conceitos para uma cena enunciativa diferente. Esse deslocamento é operado pela paráfrase na qual se reconverte o dito em um dizer, por meio da polissemia, da ambiguidade e da heterogeneidade para escamotear a noção de pecado, sempre implicada no discurso religioso e assim move os sujeitos.

Diante dessa conflagração complexa e fragmentada que são as identidades, sexualidades e os gêneros - que ganharam visibilidade na era moderna - surgem maneiras novas de pensar e praticar os discursos em relação às diferenças. Essas diferenças pressupõem um conjunto de práticas e construções discursivas no interior dos discursos, como foi demonstrado anteriormente ao longo deste trabalho, mas também pelas próprias práticas sociais, quando se opera, por meio das mesmas, táticas para desconstruir ou manter os conhecimentos construídos e presentes na linguagem - entendida como o conjunto de todos os sistemas semióticos -, mediante um conjunto de regras e convenções, mas que permite as sutilezas de táticas que levam a subversões.

Lá onde um pensamento prevê o fim da história, o outro anuncia o infinito da vida; onde um reconhece a produção real das coisas pelo trabalho, o outro dissipa as quimeras da consciência; onde um afirma os limites do indivíduo as exigências de sua vida, o outro os apaga no murmúrio da morte. (FOUCAULT, 2007, p. 386).

Se a identidade é percebida como transitória, nunca pronta e acabada, esse processo semelhante acontece em relação ao signo linguístico. Enxergado em sua devida 
complexidade, ele se instaura junto aos outros signos no campo da vida em que atua na dinamicidade e vivacidade em todos os âmbitos das relações humanas. O processo discursivo perpassa os sentidos, sempre o afetando em sua construção e desconstrução, modelado pela ação de agentes que atuam e se movem na linguagem, elaborando maneiras de ser e operar com a heterogeneidade discursiva (Foucault, 2007). Esses procedimentos resultam na múltipla e dinâmica relação de sentido do processo em eterna construção que são os sujeitos, a língua e os discursos. Como ação, Foucault (2007, p. 401) afirma que a linguagem exprime uma vontade profunda, o que tem duas consequências: a primeira é, para ele, paradoxal, pois está para um olhar mais imediato centrando a linguagem em torno do fenômeno da expressão e a segunda a qual se filia como:

[...] consequência consiste em que a linguagem não está mais ligada às civilizações pelo nível de conhecimento que elas atingiram (a finura da rede representativa, a multiplicidade dos liames que se podem estabelecer entre os elementos), mas pelo espírito do povo que as fez nascer, as anima e se pode reconhecer nelas. (FOUCAULT, 2007, p. 401).

Como afirma Foucault (2007, p. 384), “a vida escapa às leis gerais dos seres” não sendo somente "o ser uma aparência"; nessa proposição, os indivíduos sempre procuram atribuir uma verdade por meio da qual se assentam e acreditam estar contida em sua essência, a sua consciência, ou seja, o seu discurso. Isso quer dizer que, muito embora a dúvida, a impossibilidade da verdade absoluta permeie o processo de construção de sentido, é a verdade absoluta que os rege como uma mirada, um porto seguro que possa aplacar a angústia de viver sob a ameaça do erro e da dúvida, o que, aliás, é a luta de todas as epistemes, ele afirma.

A linguagem materializa todos os momentos da história e as possibilidades de destinos que emergem das relações sociais. A linguagem que organiza e que promete ser uma máquina de cálculo precisa, é a mesma que rompe "com a objetividade das coisas" estabelecendo que nada mais é que a própria "ilusão do conhecimento", sobretudo nestes tempos de aceleração da fragmentação nos quais o verbo "ser” funciona “como núcleo do ser e do não-ser: só há ser porque a vida".

Esses aspectos do processo de construção de sentido só podem emergir se nos dispormos a perscrutar o movimento e não a essência das coisas, como indicam Deleuze, Derrida e Foucault. O movimento, o eterno devir é a única essência. Nessa linha de pensamento, Deleuze (2006) nos orienta a ficar sempre em alerta ao jogo das afetações; Derrida (2007) nos indica que a escrita não é apenas representação, suplemento de uma essência, mas condições de possibilidade de realização de sentidos, e Foucault (2007) destaca 
os feixes de relações e as disputas de poder. Esses autores nos levam a considerar as relações, as rupturas e as dispersões desencadeadas pelo de desejo de poder. Os três, no entanto, colocam toda essa dinamicidade entre espaços relacionais, que se configuram como rupturas e tentativas de agrupamento, a saber, a escritura, a assemblage e as formações discursivas. Por fim, Bakhtin ajuda a pensar os feixes de relações como heterogeneidade de vozes, não apenas para implicar o aspecto coletivo e histórico do processo, mas também para chamar a atenção para a necessidade de construir espaços de pertença, uma coletividade na qual os indivíduos lutam por suas individualidades.

A maneira como o enunciado do cartaz se deu e o momento e o lugar em que foi dito, nos mostram a dinâmica e a sutiliza da interpenetração dos discursos, na formação da complexidade da rede interdiscursiva, portanto a convivência do ser humano em suas múltiplas facetas que não ocorre de forma harmônica, apesar da intenção por vezes ser essa. Aqueles que escreveram o cartaz e que o levaram à praça são sujeitos inscritos em uma formação discursiva que não falam de qualquer jeito, mas conhecem os arranjos e as regras da produção do discurso e das práticas não discursivas de uma dada formação. Eles são capazes de construir sentido nas brechas que se abrem no interior da formação à qual se filiam. Eles são capazes também de construir sentido nos interstícios entre as fronteiras das diferentes formações discursivas, o que remete a um processo interdiscursivo e a uma dinâmica de construção de objetos que lança mão de toda sorte de recurso.

As reflexões sobre o enunciado em estudo nos levam a dizer que a busca pela construção de um objeto se dá de maneira complexa, e que essa complexidade não pode ser refletida se nos concentramos apenas no significado do objeto, nas relações entre um significante e um significado, colocando em suspensão as grades, as forças que os determinam, a polifonia, os agenciamentos, etc.

Ao procurarmos refletir sobre a construção de uma verdade, buscando compreender as forças que permeiam esse processo. Isso por que, como ensina Bakhtin, não basta ser verdade, a verdade tem de ter validade. Nesse sentido, podemos dizer que, para quem está no jogo, o mais importante não é a construção do objeto em si, a verdade em si, mas uma verdade que possa ser espaço de pertença, que dê sentido não apenas ao um objeto, mas também àqueles que lutam para construir o objeto.

Parece-nos que se trata de uma de luta inevitável que necessariamente temos de travar na eterna busca pelo sentido, pois essa luta, além de nos dar uma verdade que garante uma estabilidade, ainda que parcial, abre-nos um espaço de pertencimento e uma possibilidade de 
PERcursos Linguísticos • Vitória (ES) •v. 10 •n. 25 • 2020 • ISSN: 2236-2592 • Dossiê:

Discursos de resistência e corpos (re)existentes •

romper com as origens, de buscar adeptos para esse determinado espaço, enfim, de vivenciar o inescapável: o eterno devir, o que nos parece ser mais vital do que o significado em si.

\section{Considerações posteriores}

Entendemos que as reflexões realizadas sobre o simples cartaz encontrado na praça nos possibilitaram demonstrar, ainda que de maneira parcial, a complexidade do processo de construção de sentido. O cartaz revela-se como parte de um texto maior elaborado com signos linguísticos e não linguísticos. Este foi suporte de um enunciado que nos pareceu apenas contraditório na primeira aproximação. No entanto, a análise guiada pelas reflexões dos teóricos que elegemos pode demonstrar que o sentido não ocorre de uma dedução simples, mas envolve um conjunto de forças que o determinam. Tentar compreender essa complexidade nos levou a refletir sobre as sutilezas, as manobras criativas, os desejos que permeiam o processo, mas também as forças que o determinam e que o fazem mover-se na busca de novas possibilidades, contudo, um movimento que não consegue romper totalmente com as bases sobre as quais se constituem. Entendemos que o conceito de formação discursiva de Foucault, foi de fundamental importância para refletirmos sobre a dinâmica do processo de construção de sentido que selecionamos para análise. Tal conceito nos possibilitou compreender vários fatores que concorreram para que o cartaz fosse escrito da maneira que foi. Pudemos refletir sobre questões ideológicas, semânticas e estilísticas, sem que nos detivéssemos apenas a elas. A reflexão de Deleuze sobre as possibilidades de rupturas nos remeteu à inquietude, à força que nos move diante das questões colocadas pelo mundo. Ao olhar para o cartaz, por meio de alguns conceitos de Deleuze, podemos identificar uma construção de sentido rizomática que encerra um movimento de forças centrípetas e centrífugas que possibilita a arregimentação de elementos significativos que são construídas com a mesma rapidez que se desfazem. Os conceitos de Derrida como pharmakon, escritura, jogo, brisura nos levaram a desconfiar de todos os conceitos usados no enunciado, buscando compreender as ausências, os conflitos, nas tensões que encerram e que fazem proliferar ao se relacionarem com outros conceitos, com outras ausências, etc. As leituras que temos feito de Bakhtin nos ajudaram a pensar na criatividade da manipulação da linguagem e, ao mesmo tempo, permitiu-nos pensar no dilema entre ser social, necessitar do outro, e ao mesmo tempo ter de preservar uma individualidade. Nesse sentido, o enunciado do cartaz chega a ser comovente, pois mostra, nas entrelinhas, as emoções, as potências, as determinações, as 
PERcursos Linguísticos • Vitória (ES) •v. 10 •n. 25 • 2020 • ISSN: 2236-2592 • Dossiê:

Discursos de resistência e corpos (re)existentes •

memórias, as habilidades humanas postas em ação na tessitura de uma teia de sentidos que nos envolve a todos.

Por fim, entendemos que a escolha teórica nos possibilitou demonstrar a dinâmica e a complexidade dos processos de construção de sentido a partir de um simples cartaz encontrado no chão de uma praça, depois da realização de uma manifestação em defesa da DSG e das causas LGBTQI+. A realização deste trabalho nos permitiu demonstrar, dentro de seus limites, as possibilidades de ruptura, de linhas de fuga, as estratégias para estabelecer rupturas, o exercício do poder, a criatividade para manipular a linguagem e interagir com o outro, para gerar espaços de pertença, de criar vozes a partir de outras vozes, enfim, de ser humano nessa luta entre construir verdades sempre parciais.

Entendemos que estudar os mecanismos que fazem surgir "verdades", pode ajudar a pensar e repensar em como os preconceitos, às fake news e diversas propostas de conciliação são construídas de forma sagaz e criativa, logo a melhor maneira de combater tentativas de dominação é saber que não apenas que elas existem, demonstrando seu significado, mas como funcionam em todo seu aparato como leva a pensar o pensamento rebelde, como levam a pensar as reflexões de Bakthin. E tudo isso interessa para refletirmos sobre toda sorte de enunciado, inclusive um simples panfleto jogado na calçada anunciando a vinda de um redentor transcendental ou político.

\section{Referências}

ARISTÓTELES. Arte Retórica e Arte Poética. Rio de Janeiro, RJ: Ediouro. 1979.

BAKHTIN, M. Para uma Filosofia do Ato. Toward a Philosophy of the act. HOLQUIST, Michael; LIAPUNOV, Vadim. University of Texas Press. 1993. Tradução FARACO, Carlos Alberto; TEZZA, Cristovão. Disponível em: $<\underline{\text { http://lutasocialista.com.br/livros/V\%C1RIOS/BAKHTIN,\%20M.\%20Para\%20uma\%20fi }}$ losofia\%20do\%20ato.pdf $>$. Acesso em: 14/04/2020.

BAKHTIN, M. Estética da Criação Verbal. - 2 ed. São Paulo, SP: Martins Fontes. 1997.

BARONAS, R. L. Discurso em Foucault e em Pëcheux: Notas de leitura para discussão. In Colóquio Internacional de Texto e Discurso, $1^{\circ}$ Colóquio Internacional de Texto e Discurso UENESP, Campus de Assis, 2011, p. 381-395. Versão online. Disponível em: $<$ http://www2.assis.unesp.br/fcl/livro/anais cited/files/assets/basic-html/page381.html $>$. Acesso em: 1/10/2020. 
PERcursos Linguísticos • Vitória (ES) •v. 10 •n. 25 • 2020 • ISSN: 2236-2592 • Dossiê:

Discursos de resistência e corpos (re)existentes •

DELEUZE, G, GUATARRI, F. Mil Platôs: capitalismo e esquizofrenia. - 34 ed. SP, São Paulo. Editora 34. 1996.

DELEUZE, G. Proust e os signos. - 2 ed. Rio de Janeiro, RJ: Forense Universitária. 2003.

DELEUZE, G. Diferença e repetição. Tradução: Luiz Orlandi e Roberto Machado. Rio de Janeiro-São Paulo, 2019. Paz \& Terra. 2019.

DERRIDA, J. A Farmácia de Platão. - 2 ed. São Paulo, SP: Iluminuras. 1997.

DERRIDA, J. Gramatologia. - 2 ed. São Paulo, SP: Perspectiva. 2006.

FOUCAULT, M. Estruturalismo e Teoria da Linguagem. São Paulo, SP: Vozes. 1971.

FOUCAULT, M. Em defesa da sociedade: curso no collège de France (1975-1976). São Paulo, SP: Martins Fontes. 1999.

FOUCAULT, M. Microfisica do Poder. - 5 ed. - Rio de Janeiro, RJ: Graal. 1985.

FOUCAULT, M. As Palavras e as Coisas: uma arqueologia das ciências humanas. -8 ed. São Paulo, SP: Martins Fontes. 1999.

FOUCAULT, M. A Ordem do Discurso. - 6 ed. São Paulo, SP: Edições Loyola. 2000.

FOUCAULT, M. A Arqueologia do Saber. - 7 ed. Rio de Janeiro, RJ: Forense Universitária. 2008.

GIANNOTTI, M. Uma imagem escrita. Revista ARS (São Paulo), São Paulo - SP, v. 1, n. 1, p. 91-115, Ano 2003. ISSN 1678 - 5320. Disponível em:

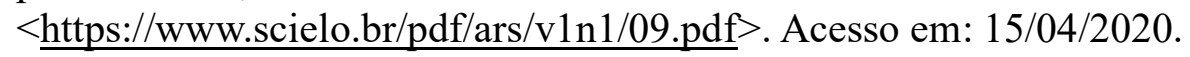

NAIL, T. What is an assemblage?. Revista SubStance (by Johns Hopkins University), Baltimore/Maryland - EUA, Volume 46, № 1, Edição 142, Ano 2017, páginas 21-37. SN -

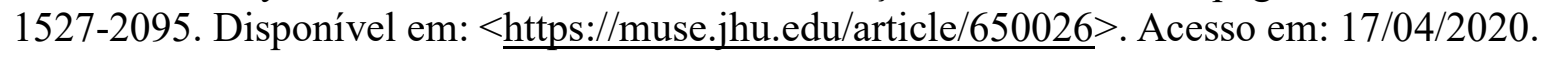

ORLANDI, E. P.. A Linguagem e o seu Funcionamento. - 6 ed. Campinas, SP: Unicamp. 1981.

O ABECEDÁRIO de Gilles Deleuse: em uma série de entrevistas com Claire Parnet (1888 1889). Direção de Pierre-André. Disponível em: $<$ www.facebook.com/watch/?v=349262982103631>. Acesso em: 20/05/2010.

SCHAEFER, S. Dialogismo, polifonia e carnavalização em Dostoiévski. Revista BAKTINIANA, São Paulo - SP, Volume 6, N 1, páginas 194 - 209, Ano 2011. ISSN 21764573. Disponível em: <https://www.scielo.br/pdf/bak/v6n1/v6n1a13.pdf $>$. Acesso em: $30 / 04 / 2020$. 